\title{
$\mathrm{PH} 100$ actuariad
}

\section{El IAPH presenta Candela Canela, el libro de los sonidos "liberados"}

El pasado 6 de marzo de 2020 se presentó en la biblioteca del Instituto Andaluz del Patrimonio Histórico el cuento infantil titulado Candela Canela, editado en digital por la Consejería de Cultura y Patrimonio Histórico de la Junta de Andalucía. Este libro llevaba gestándose dos años, a partir de la inspiradora relatoría gráfica que la artista sevillana LaMari Muriel realizó del II seminario de patrimonio inmaterial organizado por el IAPH en 2017. Sus dibujos y las conclusiones del seminario encendieron la chispa con la que este proyecto editorial comenzó a cocinarse.

María Cuéllar Gordillo | Centro de Formación y Difusión, Instituto Andaluz del Patrimonio Histórico

Url de la contribución <www.iaph.es/revistaph/index.php/revistaph/article/view/4654>

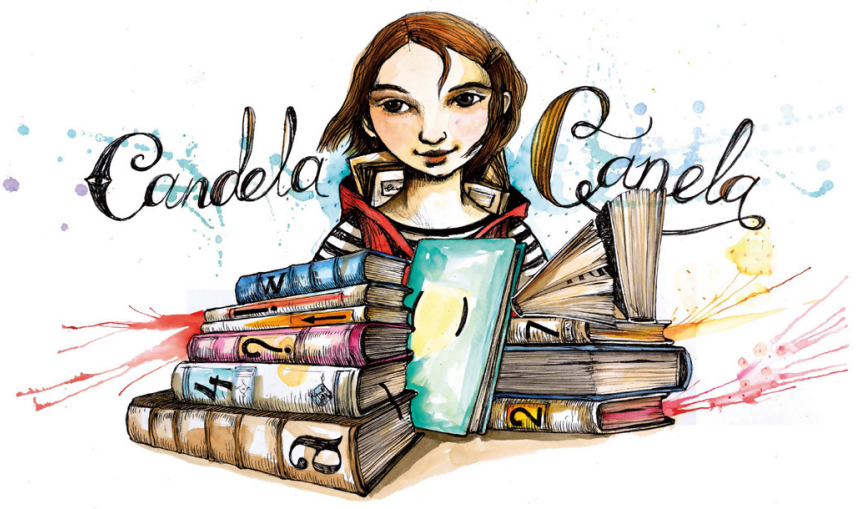

LaMari Muriel, Isabel Luque y María Cuéllar

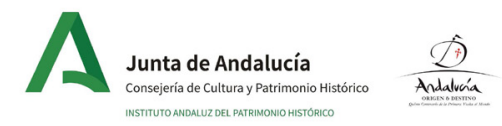

Portada del cuento Candela Canela

El II seminario de patrimonio inmaterial Los sonidos silenciados: música, danza y tradición oral en Andalucía se celebró en Sevilla del 20 al 22 de marzo de 2017, en esa segunda edición el Instituto Andaluz del Patrimonio Histórico expandió las sesiones del encuentro por la ciudad de Sevilla, salió a la calle para reunirse con los protagonistas, la ciudadanía que custodia y conserva los modos de expresión de los distintos territorios andaluces documentados en el Atlas del Patrimonio Inmaterial de Andalu- cía (2009-2014). Poner en contacto a los distintos grupos, dar a conocer los valores de la música tradicional andaluza, la riqueza de su creatividad colectiva, la diversidad y el dinamismo de sus expresiones, y debatir y favorecer estrategias para su difusión, dando, en definitiva, "voz" a sonidos muchas veces "silenciados", pero que conforman igualmente la cultura y la identidad de la comunidad, fue el objetivo conseguido en aquel seminario.

Las cuadrillas de ánimas de Los Vélez (Almería), la zambomba de Jerez de la Frontera (Cádiz), el Carnaval de Cádiz o el de Isla Cristina (Huelva), la danza de los locos de Fuente Carreteros (Córdoba), el repentismo del trovo alpujarreño, las cruces de mayo, las pandas de verdiales o la chacarrá de Tarifa, protagonizaron las distintas sesiones mostrando expresiones culturales de gran riqueza. Todos los grupos tenían mucho en común, entre otras cosas, algo muy básico: los integraban personas de varias generaciones. $Y$ los relatos compartidos hablaban de identidad y de comunidad, se construían sobre conceptos como memoria, apropiación, transmisión, adaptación, evolución y también cambio. Se habló de lo viejo y de lo nuevo.

Pero toda esa riqueza cultural es muy poco conocida más allá de las comarcas en las que se crea, y la difusión que se hace por parte de las instituciones, normalmente, no está pensada ni dirigida a niños y niñas, que son hoy, sin duda, los ciudadanos más interesados en escuchar y aprender, y el día de mañana la ciudadanía sobre la 
que recaerá el peso de la conservación, la salvaguarda y la toma de las mejores decisiones. Y esas, siempre, se sustentan sobre el conocimiento y la emoción.

Precisamente eso motivó al Instituto Andaluz del Patrimonio Histórico (IAPH) a impulsar este proyecto editorial dirigido a los más jóvenes. Un cuento simple que encierra "un mundo".

Candela Canela, editado en formato digital y disponible a través de las Tiendas Culturales de Andalucía y, para libre descarga, en el sitio web del Instituto Andaluz del Patrimonio Histórico, se construye con las ilustraciones de LaMari Muriel, los textos de Isabel Luque Ceballos y María Cuéllar Gordillo, ambas del Departamento de Formación y Difusión del IAPH y con la coordinación científico-técnica de Gema Carrera Díaz, del Centro de Documentación y Estudios del IAPH.

La actividad de presentación de este libro infantil, fue diseñada y realizada por Piratas de Alejandría, y congregó en la biblioteca del IAPH, el pasado 6 de marzo, a la clase de $5^{\circ} \mathrm{B}$ del CEIP José María del Campo (Sevilla), un público entusiasta que disfrutó con un cuentacuentos hecho a su medida, que combinaba el descubrimiento por parte de los niños y niñas de la biblioteca como lugar de conocimiento y disfrute, y del patrimonio inmaterial como parte del pasado compartido, de la identidad colectiva y del dialogo intergeneracional.

\section{La amenaza del olvido}

Candela Canela es una niña a la que le encanta leer, ella dice que cuando lee, viaja. Lo hemos escuchado muchas veces, abrir un libro es abrir una ventana por la que ¿mirar otras realidades? ¿escapar de la propia? Si tuviéramos que colocar en una línea del tiempo imaginaria dónde se encuentra, mentalmente, la persona mientras lee, ese apunte lo haríamos, instintivamente hacia delante, siempre más allá, otro lugar, un deseo, un sueño, ¿el futuro? Ciertamente la lectura también podría trasladarnos a una proyección del pasado, pero la propia definición de "proyectar" nos hace mirar hacia delante.

Entonces, Candela, que es la niña que "viaja" con la lectura, se va a otro lugar, tan distante y alejado, que queda

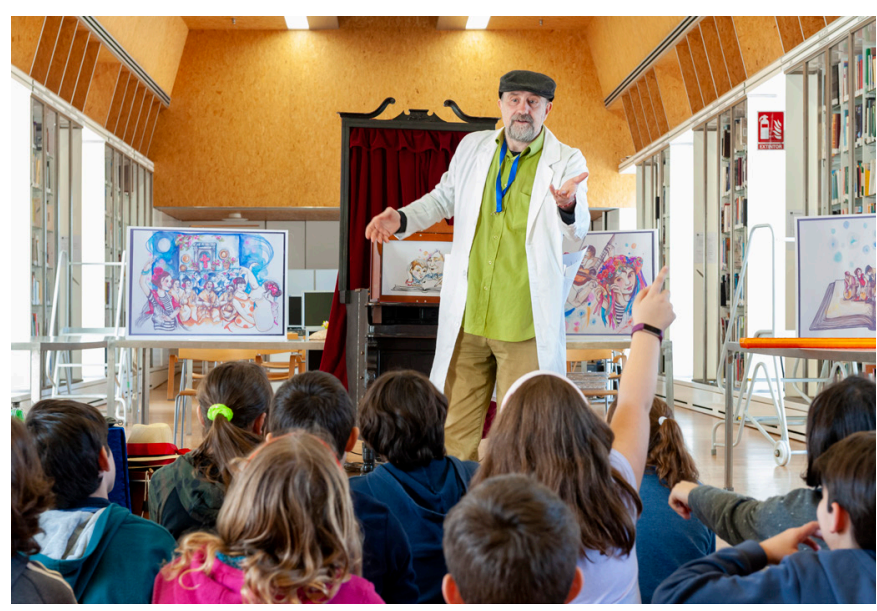

Presentación teatralizada de Candela Canela en la Biblioteca del IAPH a cargo de la empresa Piratas de Alejandría

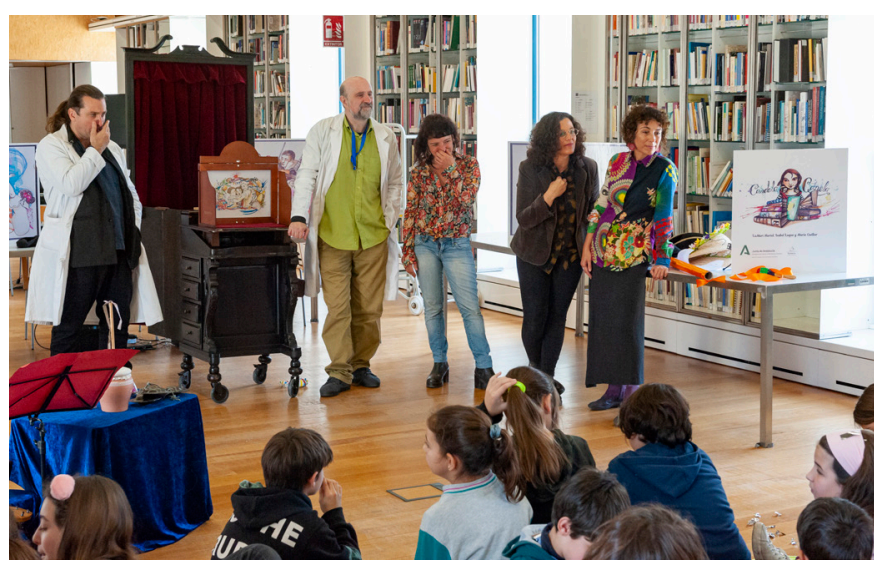

Acompañaron la presentación del cuento parte de sus creadoras: LaMari, Gema Carrera e Isabel Luque

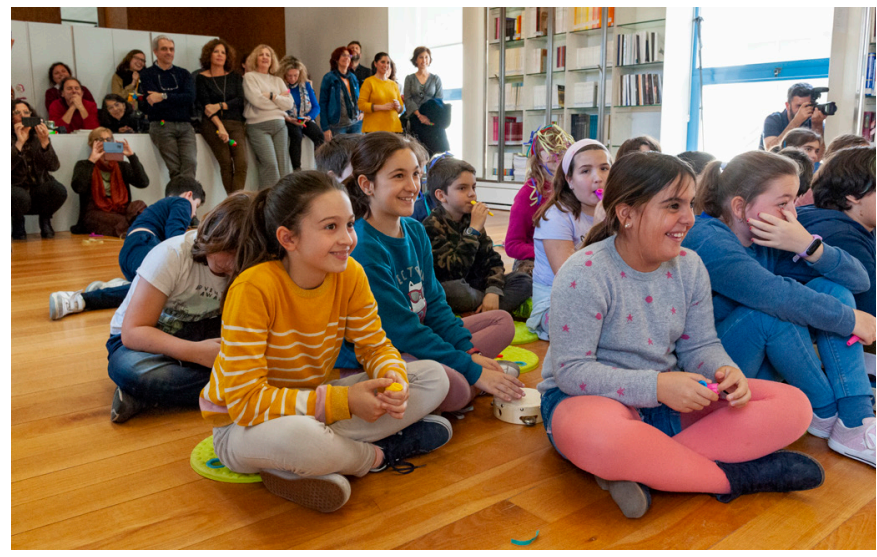

Alumnado del CEIP José María del Campo (Sevilla) con trabajadores del IAPH al fondo | fotos Fondo Gráfico IAPH (José Manuel Santos Madrid) 


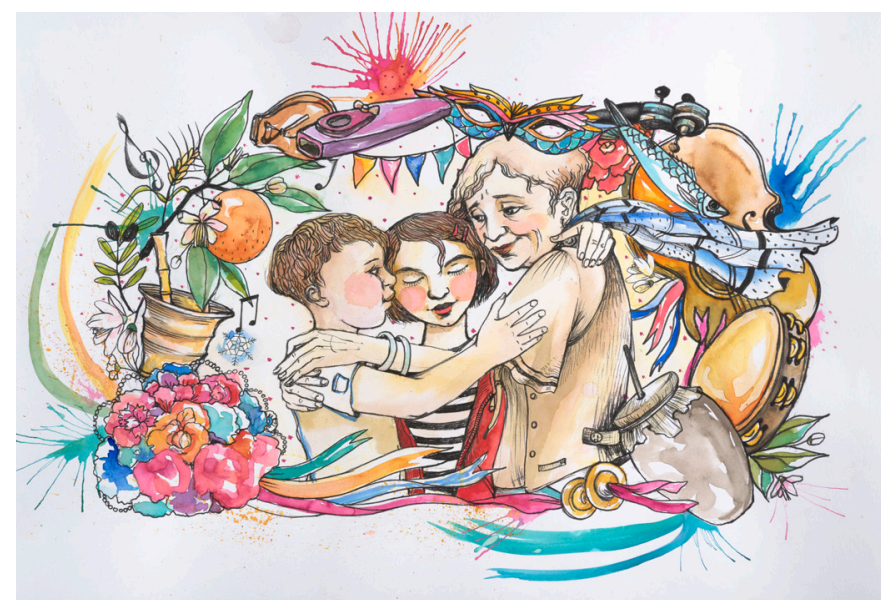

Ilustraciones de LaMari dan belleza y color a las palabras y versos de las autoras de Candela Canela: Isabel Luque y María Cuéllar

atrapada en un "no lugar", un libro en blanco, la nada. $Y$ allí, sin referencias, se desorienta y pierde su identidad. Se olvida de quién es. Porque sin memoria no hay pasado, ni presente, ni futuro.

Fuera, en la biblioteca, ese "lugar" que contiene todo el saber y todas las posibilidades, dos generaciones, el hermano menor, al que Candela le abrirá camino y la abuela, que debe ir abriéndoselo a ella, intentan sacarla del libro, hacerla volver.

¿Cómo lo consiguen? Recordando, porque el recuerdo es la continuación del pasado en el presente, y hace posible la perspectiva de futuro.

\section{Recordar para comprender, recordar para aprender,} recordar para avanzar

Candela lo ha olvidado todo, pero su abuela, gracias a los sonidos que salen del libro, que activan su memoria, empieza a recordar y a reconocer lo que está escuchando como la música, las fiestas y las tradiciones que la acompañaron cuando era niña y conformaron su mundo. $Y$ mientras recuerda, el libro se va escribiendo. Esto ayudará a que vuelva su nieta, le enseñará el camino a casa:

"Le había ganado la batalla al olvido, había recuperado sus recuerdos de la infancia, y un poco se había recuperado también a ella misma."
Candela, mientras tanto, recorre las páginas de un libro que estaba vacío, pero que su abuela ha escrito con música, danzas, experiencias compartidas y sentido. $Y$ volverá, pero distinta, porque ha aprendido:

"Candela miró al cielo de una página que no era blanca ya. En su cielo encontró su historia, a su hermano y a su abuela. Y supo quién era: Soy Candela Canela."

En la Convención para la Salvaguarda del Patrimonio Cultural Inmaterial de UNESCO (2003) leemos "Este patrimonio cultural inmaterial, transmitido de generación a generación, es constantemente recreado por comunidades y grupos en respuesta a su entorno, su interacción con la naturaleza y su historia, y les proporciona un sentido de identidad y continuidad, promoviendo de este modo el respeto por la diversidad cultural y la creatividad humana".

Porque el patrimonio cultural no es solo memoria acumulada que construye nuestra identidad. La memoria no solo responde al impulso de la permanencia, sino también al de trascendencia, no es únicamente acumulación, también es aprendizaje. La memoria está viva y en constante pique y replique con el olvido, por eso hay avance, pero con bagaje:

"Quintillas y rimas, coplas y zambombas, violines y panderetas.

Lo que bailó una abuela debe saberlo una nieta. Que nada bueno caiga en el olvido, eso os pido.

Recordad lo que sabéis

y aprended miles de cosas.

De lo viejo nace lo nuevo,

¿no es ese el sentido de esta historia?"

Candela Canela, 2019 